\title{
O papel dos grupos de apoio e o compartilhamento da informação e do conhecimento nas avaliações das instituições de ensino superior privadas.
}

\section{Armando Sérgio de Aguiar Filho}

\section{Doutorando em Ciência da Informação pela Universidade Federal de Minas Gerais}

Mônica Erichsen Nassif

\section{Doutora em Ciência da Informação pela Universidade Federal de Minas Gerais}

http://dx.doi.org/10.1590/1981-5344/2822

Este artigo é resultado de uma tese cujo objetivo foi analisar as práticas de compartilhamento da informação e do conhecimento em estruturas de Grupos de Apoio de Instituições de Ensino Superior Privadas, em seus processos de avaliações institucionais, de forma a perceber a existência de um comportamento preponderante. O trabalho foi desenvolvido a partir de pesquisa bibliográfica, tendo como foco o levantamento e a apresentação dos estudos relativos aos canais de compartilhamento da informação e do conhecimento, procurando identificar seus correlatos na área da administração. Na pesquisa utilizou-se metodologia mista qualitativa e quantitativa de estudo de casos múltiplos. 0 contexto da pesquisa foi o ensino superior privado, desenvolvendo-se estudos de caso em sete instituições do Estado de Minas Gerais. A pesquisa indicou considerações relevantes quanto ao entendimento das diversas abordagens utilizadas no que tange aos canais de compartilhamento, assim como as características comuns e diferenciadas destes meios e os impactos em suas dinâmicas que, analisadas em diferentes contextos, permitem avaliar e promover serviços de informação mais adequados para atender demandas específicas. Os resultados da coleta de dados com os sete Gestores dos Grupos de Apoio das instituições analisadas, e quarenta e quatro participantes desses grupos, demonstraram fortes 
evidências que, de fato, o compartilhamento do conhecimento gerado no Grupo de Apoio contribui para a melhoria dos processos de avaliações institucionais.

Palavras-Chave: Gestão do conhecimento; Compartilhamento da informação e do conhecimento; Grupo de apoio; Ensino superior privado.

\section{The role of the support groups and sharing information and knowledge in institutional reviews of private higher education institutions.}

This article is the result of a thesis that analyzes the sharing of practical information and knowledge in Higher Education Institutions Support Groups structures Private, in their processes of institutional evaluation, in order to realize the existence of a dominant behavior. The work was developed from literature, focusing on the collection and presentation of studies on information sharing channels and the knowledge, seeking to identify its correlates in the area of administration. In research we used qualitative and quantitative mixed methodology study of multiple cases. The context of the research was the private higher education, developing case studies in seven institutions of the State of Minas Gerais. Research has indicated considerations relevant to the understanding of the various approaches used in relation to the sharing of channels, as well as the common and different characteristics of these media and the impact on their dynamics, analyzed in different contexts, to assess and promote information services more tailored to meet specific demands. The results of data collection with the seven Managers of Support Groups of institutions analyzed, and forty-four participants of these groups have shown strong evidence that, in fact, the sharing of knowledge generated in the Support Group contributes to the improvement of processes institutional evaluations.

Keywords: Knowledge management; Sharing information and knowledge; Support group; Private higher education. 


\section{Introdução}

As transformações sociais e organizacionais da Era do Conhecimento têm exigido das empresas uma capacidade de aprendizagem cada vez maior. Associa-se a isto a crescente utilização e difusão da informação, que tem proporcionado mudanças importantes nos mais diversos setores da sociedade, tornando a gestão da informação um recurso fundamental para as organizações. Nesse sentido, a informação passa a ser tratada como recurso tão fundamental quanto o capital, a mão-de-obra e a tecnologia, sendo, portanto, considerada um ativo de grande relevância para agregar valor aos processos, produtos e serviços prestados pelas organizações. O conhecimento é o recurso econômico mais valioso para a competitividade das empresas e das nações e seu uso como fonte de vantagem competitiva sempre existiu. Assim, a aprendizagem, geração e compartilhamento do conhecimento não seria um novo pensamento revolucionário, mas sim, algo que as empresas sempre fizeram, porém, atualmente, com um nível maior de sofisticação.

A expressão "gestão do conhecimento" é utilizada há mais de duas décadas, no entanto é cada vez maior a necessidade de colocá-la em prática por duas razões: a primeira devido ao fato de que o capital intelectual passou a ser considerado um diferencial competitivo que pode colaborar para a sobrevivência no atual mercado econômico e a segunda, porque a necessidade de identificar, organizar, armazenar e proteger 0 conhecimento tornou-se imprescindível diante da acirrada concorrência estabelecida no ambiente empresarial.

Conforme Davenport e Prusak (1998) o benefício do conhecimento é proporcionar uma vantagem sustentável gerando retornos crescentes e continuados e, ao contrário dos ativos materiais, ele aumenta com o uso: ideias geram novas ideias e o conhecimento compartilhado permanece com o doador, ao mesmo tempo em que enriquece o recebedor. Como a informação tem sido vista pelas instituições como um recurso capaz de agregar valor aos produtos e serviços por elas prestados, não basta às organizações possuírem informações de qualidade, é necessário disponibilizá-las adequadamente para o público certo, no tempo certo. Isso implica em saber como obter a informação, como organizá-la e como distribuí-la, ou seja, implica em uma preocupação quanto ao gerenciamento da informação nas organizações. Drucker (1993), em sua análise de gestão da informação no ambiente empresarial evidencia que a organização tem que aprender a criar novos conhecimentos por meio da melhoria contínua de todas as suas atividades, mediante 0 desenvolvimento de novas aplicações com base em seus próprios sucessos e mantendo a inovação como processo organizado, visando responder ao desafio de aumentar continuamente a produtividade dos trabalhadores do conhecimento. 
Para obterem sucesso em ambientes de constantes e profundas mudanças, as organizações precisam reexaminar suas estratégias e questionar seus processos informacionais. Os Gestores têm sido chamados a empreender esforços no sentido de compreender $e$ interpretar a natureza dessas mudanças e de analisar as implicações para as suas empresas. Neste contexto, emerge o papel do compartilhamento da informação e do conhecimento que tende a provocar uma nova leitura dos canais de distribuição, possibilitando o amadurecimento do conceito de compartilhamento e sua relação com o processo de gestão da informação. Dessa interação surge variada gama de alternativas paras as organizações se relacionarem internamente com seus colaboradores e, externamente, com o seu público.

Segundo Choo (2003), em uma organização o conhecimento é amplamente disseminado e toma várias formas, mas sua qualidade é revelada na diversidade de capacitação que a organização desenvolve como resultado desse conhecimento. Para ele a eficácia do processo pode ser melhorada por meio de iniciativas de gerenciamento sistemático.

Uma das abordagens propostas para prática do compartilhamento da informação e do conhecimento é a do Grupo de Apoio que, para Tavares (2011), tem como principal objetivo contribuir para o processo de tomada de decisão, certificando-se de que as informações sejam oportunas, tenham relevância e propósito e mantenham-se com a qualidade e quantidade necessárias. Para o autor, a fim de atender as demandas do mercado e em função da competitividade e da produtividade observa-se a aproximação do modelo de oferta educacional ao funcionamento da economia com a aplicação de conceitos originários do meio econômico, como eficiência, produtividade, relações de mercado, clientelas e preferências dos consumidores ao meio educacional. A busca pela produtividade, eficiência e eficácia institucional levam as instituições à revisão dos modelos e metodologias com vistas ao planejamento e tomada de decisões, utilizando como principal recurso a informação e o conhecimento.

\section{Conhecimento como vantagem competitiva}

De acordo com Davenport e Prusak (1998) a vantagem do conhecimento é uma vantagem sustentável. Para eles com o tempo, os concorrentes quase sempre conseguem se igualar, mas a empresa rica em conhecimento e gestora do conhecimento terá passado para um novo nível de qualidade, criatividade e eficiência. Ao contrario dos ativos materiais, que diminuem à medida que são usados, os ativos do conhecimento tendem a aumentar com a sua utilização. É importante destacar que o potencial de novas ideias surgidas do estoque do conhecimento de uma empresa é praticamente infinito, em especial se as pessoas da empresa têm a oportunidade de pensar, aprender e conversar umas com as outras. Choo (2003) contribui para a discussão do conhecimento como vantagem competitiva explicando que a simples 
existência de conhecimento em na organização é de pouca ajuda, uma vez que ele só é um ativo corporativo valioso quando está acessível e seu valor aumenta na proporção do grau de acessibilidade. 0 papel estratégico do conhecimento é também identificado por Nonaka (1997), para quem o conhecimento é valioso se for aplicável com êxito em atividades criadoras de valor/competências e for utilizável na exploração de oportunidades de negócios.

O compartilhamento do conhecimento amplia a capacidade de inovação e gera fontes de vantagem competitiva. Assim, Nonaka e Takeuchi (1996) concluem que o conhecimento torna-se um diferencial competitivo porque à medida que as companhias buscam novas formas de alavancar seus recursos para ganhar mais vantagens competitivas, a consciência de que o conhecimento que existe dentro de uma empresa é um de seus recursos mais importantes, aumenta.

A gestão da informação e do conhecimento é fundamental para as organizações se tornarem competitivas. A falta de uma estrutura organizacional sensível e atenta à gestão da informação impede a sinergia entre os diferentes setores, tanto em virtude do excesso como da falta de informação, ou mesmo o acesso de forma inadequada aos conteúdos informacionais pode levar os membros da organização a trabalhar com elevados níveis de tensão e imprecisão. Gerenciando a informação de forma integrada, a fim de usá-la no momento da tomada de decisão, as organizações desenvolvem processos e fluxos dinâmicos que possam buscar seu crescimento e evolução, contribuindo para a seleção e filtragem da informação que é mais adequada e relevante à tomada de decisão.

Davenport e Prusak (1998) descrevem que ainda os tomadores de decisão tenham acesso a uma grande quantidade de informações, a maioria presta atenção a determinados tipos, como por exemplo, financeiras, operacionais e mercadológicas; ou seja, a informação que de algum modo, esclareça melhor as incertezas estratégicas dos ambientes interno e externo à corporação. Isso não é uma regra: existem organizações que dão ênfase às informações dos clientes, dos concorrentes tradicionais e não-tradicionais, informações internas e, dependendo do ramo de atividade, definem sua estratégia de informação com informações de produtos gerados internamente, informações conseguidas junto aos fornecedores e parceiros, aperfeiçoamento da informação logística e informações dos próprios funcionários.

Nas palavras de Carvalho (2009) gerenciar informação como um recurso organizacional, implica primeiramente em verificar as necessidades informacionais dos indivíduos da organização, na segunda etapa prospectar e coletar o que é relevante, em terceiro selecionar (filtrar), organizar, tratar, armazenar, e por último disseminar, transferir e gerar novas necessidades. Torna-se assim necessário buscar metodologias e ferramentas para desenvolver essas atividades de maneira eficiente, a fim de gerar conhecimento e inteligência, visando subsidiar o processo decisório. 


\section{Criação e compartilhamento do conhecimento}

Para Nonaka e Takeuchi (1997), o desenvolvimento de uma organização está intimamente relacionado à sua capacidade de criar conhecimentos, disseminá-lo na organização e incorporá-lo a produtos, serviços e sistemas. Esse processo ocorre dentro de uma comunidade em interação que se expande, atravessando níveis e fronteiras interorganizacionais. O modelo dinâmico da criação do conhecimento está fundamento no pressuposto de que este é criado e expandido por meio da interação entre as dimensões tácito e o explícito, mediante quatro processos de conversão: socialização, externalização, combinação e internalização.

a)socialização: converte o conhecimento Tácito em Tácito, por meio do compartilhamento de experiências, o aprendizado pela observação, imitação e prática;

b)externalização: o conhecimento Tácito para o Explícito. È um processo de criação do conhecimento expresso nas metáforas, analogias, conceitos, hipóteses e modelos;

c)combinação: conhecimento Explícito em Explícito. Processo de sistematização de conceitos em um sistema de conhecimento. As pessoas trocam conhecimentos através de documentos, reuniões, redes de computadores, conversas ao telefone;

d)internalização: conhecimento Explícito para Tácito. Estar relacionado ao "aprender fazendo", sendo necessárias a verbalização e diagramação do conhecimento na forma de manuais ou histórias orais.

Desta forma a criação do conhecimento organizacional se dá pela interação contínua e dinâmica entre o conhecimento tácito e o explícito, que, por sua vez, é moldada pelas mudanças entre diferentes modos de conversão. Para Nonaka e Takeuchi (1997), esses quatro modos constituem o motor do processo de criação do conhecimento como um todo, sendo os mecanismos pelos quais o conhecimento individual é articulado e amplificado na organização.

É difícil transferir ou disseminar grande volume de conhecimentos, sobretudo do tipo tácito, dentro da organização. Enquanto o conhecimento explícito é divulgado mediante ferramentas de rede ou de groupware, a transferência do tácito exige compartilhamento mediante socialização, proximidade física e bons relacionamentos, embora vários softwares de colaboração sejam extremamente úteis para apoiar o processo (NONAKA, 2001).O modelo de criação do conhecimento serve como um guia às organizações que desejam promover ou mesmo gerenciar o processo de criação do conhecimento mas algumas ressalvas devem ser feitas, em 
especial quanto a diferenças de vários fatores, como: pessoas, lugares, procedimentos e ambientes.

Segundo Davenport e Prusak (1998) há vários fatores que inibem a transferência do conhecimento: falta de confiança mútua, diferentes culturas, vocabulários e quadros de referência, falta de tempo e de locais de encontro; ideia estreita de trabalho produtivo, status e recompensas vão para os possuidores do conhecimento, falta de capacidade de absorção pelos recipientes, crença de que o conhecimento é prerrogativa de determinados grupos, síndrome do "não inventado aqui", intolerância com erros ou necessidade de ajuda.

\section{Os canais de compartilhamento da Informação e do Conhecimento}

De acordo com Choo (2003), em uma organização o conhecimento é amplamente disseminado e toma várias formas, mas sua qualidade é revelada na diversidade de capacitação que a organização desenvolve como resultado desse conhecimento. Davenport e Prusak (1998) expõem que o conhecimento é transferido nas organizações, quer esse processo seja gerenciado, quer não, pois seu compartilhamento está no cotidiano organizacional. Mas, a eficácia do processo pode ser melhorada por meio de iniciativas de gerenciamento sistemático. Os autores salientam que compartilhar não deve ser confundido com relatar, que é uma troca involuntária de informações e conhecimento, de maneira rotineira ou estruturada. Eles ressaltam que os métodos de transferência do conhecimento devem ser compatíveis com a cultura organizacional e destacam como aspecto importante do sucesso de qualquer projeto de compartilhamento a existência de linguagem comum entre os participantes.

Nisembaum (2002) colabora para a discussão ao identificar três dimensões relevantes na escolha do método de compartilhamento de conhecimento: as características do receptor do conhecimento, tanto em termos de tarefa quanto de contexto, a natureza da tarefa, conforme sua frequência e rotina, e o tipo de conhecimento a ser transferido. Teóricos da Administração, a exemplo de Davenport (1999) e de Stewart (1998), apontam um novo direcionamento do processo de compartilhamento, voltado principalmente às questões relacionadas à transmissão da informação. Para os autores, a transferência da informação envolve duas ações: transmissão (envio ou apresentação da informação a um receptor potencial) e absorção por aquela pessoa ou pelo grupo. Se a informação não for absorvida, ela não terá sido transferida. Assim, isoladamente, a disponibilização da informação não assegura a sua efetiva transferência. 0 acesso é necessário, mas não é suficiente para garantir a compreensão e o uso da informação.

Assim, sempre que os canais de compartilhamento disponíveis forem primitivos em relação à necessidade de informação, o será também o sistema como um todo. Por contraste, quanto maior a eficiência dos 
canais maior a utilização deles como instrumento de distribuição da mensagem /informação. Um compartilhamento adequado ocorre quando a informação flui por toda a organização, alcançando os distintos níveis hierárquicos. Para tanto, é preciso utilizar os meios mais adequados, ou seja, os canais mais apropriados. Um adequado compartilhamento deve permitir à organização conhecer-se melhor, o que envolve, dentre outros aspectos, aquele que diz respeito ao funcionário ter acesso às informações necessárias ao adequado desenvolvimento de suas funções. Vale ressaltar ainda, a importância da capacidade do funcionário de interpretar tais informações e utilizá-las em prol da melhoria dos serviços prestados pela instituição.

Para Nonaka e Takeuchi (1997), a criação do conhecimento organizacional deve ser entendida como um processo que amplia organizacionalmente 0 conhecimento criado individualmente. Nas organizações, as pessoas podem compartilhar o conhecimento tácito e explícito, de maneira formal (relatórios, manuais, etc.) e informal (batepapo com colegas, por exemplo).

\section{Grupos de Apoio e demais abordagens}

Muitas são as definições de grupos. Muitos também são os termos utilizados com os mesmos significados. Segundo Adler (2006) grupos são duas ou mais pessoas que interagem e se influenciam diretamente, são mutuamente dependentes e têm papeis entrelaçados e normas comuns, e que se veem mutuamente como uma unidade na busca de objetivos comuns que satisfaçam suas necessidades e aspirações individuais.

Os indivíduos estando ou não inseridos em grupos, tem insights e flashes, reorganizando uma determinada experiência, através de determinados estímulos do ambiente. Estes insights, derivados de um aprendizado cognitivo, se tornam úteis para as organizações a partir do momento que são interpretados e compartilhados pelo grupo, subsidiando a resolução de determinados problemas ou o desenvolvimento de determinados produtos e da inovação. Porém, as pessoas, ao fazerem parte de um determinado grupo, são responsáveis pelo seu crescimento e somente elas poderão ver sentido em suas ações perante o grupo. Deste modo, sua participação de maneira ativa ou passiva, colaborando ou não, no compartilhamento de experiências com este grupo, depende de suas escolhas e de seu estado interior.

Adler (2006), em estudos com grupos colaborativos que enfrentam desafios necessários para que possam melhorar o trabalho nas empresas onde estão empregados, perceberam que estes desafios interligam e envolvem as pessoas. Os autores acreditam que devido ao motivo da atividade desses grupos ser de necessidade coletiva, porque sua realização irá fluir em benefício de todos, os impasses, que eles denominam de limites são mais fáceis de serem compreendidos do que os limites das comunidades tradicionais, nas quais os sujeitos têm uma pluralidade de necessidades e motivos. Estes autores apontam benefícios 
no compartilhamento do trabalho em grupo, entre eles a participação e as relações positivas entre pessoas de diferentes credos, raças, idades, naturalidades, nacionalidades e classes sociais, o valor da cooperação e da tomada de decisão conjuntas construídas na participação democrática, a importância da iniciativa individual dentro do grupo, a liberdade de participar expressando pensamentos e sentimentos sobre assuntos que dizem respeito ao indivíduo do grupo ou do grupo como um todo, tendo o direito de se envolver no processo de tomada de decisões, empoderamento, que é valorizar o poder do grupo em ajudar seus membros a se sentirem bem, de tal forma que consigam usar suas habilidades e peculiaridades em favor de fazer a diferença em suas comunidades. Para estes autores quanto mais claros os participantes do grupo tiverem seus objetivos e valores em relação à sua participação no grupo, ou seja, em relação ao objeto que deva ser compartilhado, mais fácil será para atravessarem objetivos conflituosos e deixarem seus objetivos bem claros para o grupo.

Francis e Young (1992) definem como importantes membros de um grupo aqueles que assumem os problemas que deverão enfrentar, bem como os desafios que aparecem, exploram, esclarecem e propõem objetivos, esclarecem critérios que objetivam sucesso nas ações do grupo, coletam e estruturam informações que sirvam como opções para ações, desenvolvem planos e estratégias e reveem o aprendizado e procuram melhorar a performance.

Nonaka (1999) defende a ideia de um espaço de conhecimento compartilhado que encoraja e fomenta a participação em muitos níveis diferentes, promovendo a convivência. O autor traz a definição de contexto capacitante, que é a criação de espaços para criação do conhecimento, promovendo interações entre os membros da organização por meio de forças-tarefas, equipes e seminários. Os contextos capacitantes também surgem por geração espontânea. Aproxima-se deste conceito o de comunidade de prática, citado por Wenger (1998). Práticas de comunidade de prática implicam que os indivíduos aprendam com a participação nas práticas grupais. As fronteiras da comunidade de prática são definidas com nitidez pelas tarefas, cultura e história, já o contexto é caracterizado por seus participantes e pode ser mudado com facilidade. $\mathrm{Na}$ comunidade a composição é bastante estável e no contexto os membros entram e saem do grupo. Já que o conhecimento se torna uma fonte de vantagem competitiva, o processo de aprendizagem adquire especial relevância para a formulação de estratégias e para as demais ações que visam aumentar a competitividade da empresa. A criação de comunidades de prática visa proporcionar tais condições. Complementarmente, Leehesvirta (2004) considera que estas condições advêm de quatro subprocessos: intuir, interpretar, integrar e institucionalizar. A intuição ocorre a nível individual, quando determinados insights ou ideias vêm na mente de determinada pessoa. Estas ideias são interpretadas a um nível grupal, utilizando-se de determinada linguagem comum, significados compartilhados e compreensão. Quando o grupo 
passa a realizar uma determinada ação sobre o que foi interpretado, de uma maneira coletiva, há uma integração do aprendizado. Na fase final, que é a institucionalização, o que é aprendido por indivíduos e grupos, torna-se embutido nas estruturas e processos da organização e, portanto, começa a guiar o aprendizado novo, espontâneo e individual, e, o aprendizado no nível do grupo. Esta estruturação em diferentes níveis facilita a compreensão do papel das comunidades de prática no nível organizacional. Wenger e Snyder (2001) esclarecerem que, embora sejam auto-organizadas e, portanto, resistentes à supervisão e à interferência, requerem esforços gerenciais para desenvolvê-las e integrálas à organização. Para eles não existe um modelo de organização das comunidades de prática, algumas se reúnem no almoço, outras se comunicam por grupos de discussões, por reuniões semanais ou esporádicas, face a face ou através da Internet.

Nela os participantes compartilham compreensões sobre o que estão fazendo e o que isso significa em suas vidas e ambientes. O que impulsiona de fato as comunidades de prática são os objetivos comuns e a necessidade de aprender uns com os outros formando o saber coletivo. Para Fleury (2001) os colaboradores necessitam trocar experiências com seus colegas e envolver esforços consideráveis para reunirem-se, partilharem histórias e construírem um conhecimento que os ajude a enfrentarem os problemas que surgem. Ser membro de uma comunidade de prática implica partilhar com os companheiros um processo contínuo de aprendizagem; implica não somente geração de conhecimentos, mas também de identidade.

O contexto de compartilhamento em práticas de grupo surge na abordagem de Prusak e Davenport (1998) através das redes informais. Para eles é possível que as melhores práticas do conhecimento fluam pelas redes informais que se desenvolvem nas organizações. Grande parte do trabalho nas empresas é feito porque as pessoas estão continuamente perguntando umas às outras através de redes informais quem sabe como fazer determinado trabalho. As redes informais têm vantagens e desvantagens, próprias da informalidade. Por funcionarem através de contatos informais e informação boca a boca, elas geram confiança que é a base essencial para o intercambio do conhecimento, além disso, são dinâmicas. A desvantagem é que por serem informais e não documentadas, não estão prontamente acessíveis a todos que precisam delas. Sua viabilidade depende de conversas casuais e contatos locais que por vezes funcionam bem, mas outras vezes, não.

$\mathrm{Na}$ administração a abordagem de contextos capacitantes, comunidades de práticas e redes informais é apresentada por Tavares (2011) com a nomenclatura de Grupos de apoio. Para ele o processo de gestão estratégica nas organizações necessita de um arranjo que busque a governabilidade da organização face ao que se pretende dela. Este processo deve abranger as dimensões pessoais, funcionais e de recursos que permeiam todas as áreas da organização. A formalização de um grupo de apoio deve estar subordinada a determinadas condições: o grupo deve 
ser constituído por pessoas que estejam diretamente envolvidas e comprometidas, de algum modo, com o presente e com o futuro da organização. Entre algumas de suas condições essenciais, os participantes devem ter uma visão conceitual da organização e do setor, ter uma visão crítica da organização, ter credibilidade junto aos colegas e subordinados, representarem todas as áreas envolvidas no processo e serem capazes de cumprir os compromissos assumidos. As pessoas que fazem parte da composição deste grupo possuem algumas responsabilidades como difundir o processo, compartilhar e disseminar o conhecimento, obter participação e envolvimento de seus colegas, indicar pessoas para participar em momentos específicos do processo, identificar problemas e disfunções e contribuir para que os mesmos sejam eliminados, minimizados ou mantidos sobre controle. A tarefa do grupo é catalisar o processo, certificando-se de que as informações sejam oportunas, tenham relevância e propósito e mantenham a qualidade e quantidade necessárias para orientar a tomada de decisão. O grupo também busca a criação de um clima favorável e a busca sistemática do comportamento proativo da organização. O autor destaca que nos grupos de apoio é necessário diferenciar participação de engajamento. São ações diferentes. Estar engajado significa não só participar, como também sentir-se plenamente responsável por fazer com que um objetivo se realize. Participar não requer, em si, comprometimento ou engajamento.

Concomitantemente aos conceitos de participação e engajamento, faz-se necessário analisar a perspectiva de envolvimento e comprometimento das pessoas que fazem parte do grupo de apoio. 0 envolvimento representa a identificação das pessoas com a proposta, enquanto o comprometimento refere-se ao estabelecimento e cumprimento de compromissos em relação ao que se propõe a realizar. A percepção do grupo é em grande parte um somatório das percepções de cada um dos envolvidos no processo. Á medida que cada um explicita seu grau de comprometimento fica mais fácil avaliar as perspectivas de sucesso do processo de compartilhamento.

Uma vez agrupados e engajados, os membros do grupo de apoio devem estar capacitados para o desenvolvimento das seguintes atividades:

a)monitoramento do ambiente externo, tanto no nível macro como junto aos relacionamentos externos e ambiente competitivo da organização;

b)monitoramento interno, compreendendo a constante adequação da organização para responder aos desafios e demandas do ambiente externo;

c)recomendação da necessidade de elaboração e coordenação da execução de planos específicos;

d)implementação de mudanças sugeridas nesses cursos de ação; 
e)acompanhamento e avaliação das atividades desenvolvidas para o cumprimento das decisões tomadas no âmbito do grupo.

\section{0 cenário competitivo das instituições de ensino superior privadas e o Sistema Nacional de Avaliação Superior (SINAES) e seus processos avaliativos}

Em 2014, o Brasil representava o quinto maior mercado de ensino superior do mundo e o maior mercado de ensino superior da América Latina, com mais de 7,0 milhões de matrículas, segundo dados do Ministério da Educação e Cultura (MEC). Existiam ainda 2.416 estabelecimentos de ensino superior no Brasil, de acordo com o MEC. Do total de alunos matriculados em, 27\% estavam em instituições de ensino públicas e 73\% em instituições de ensino privadas. Entre 2010 e 2014, as instituições de ensino superior privadas apresentaram crescimento de $21 \%$ no número de matrículas, passando de 4,3 milhões de alunos em 2018 para 5,1 milhões de alunos em 2014, de acordo com o MEC. O crescimento econômico, a globalização e o consequente aumento da renda no Brasil nos últimos anos elevaram significativamente a demanda por mão-de-obra qualificada, resultando em maior dispêndio da população com educação e qualificação. Neste período houve sucessivo aumento no número de matrículas concentradas nos cursos de bacharelado, de licenciatura e tecnológicos.

Apesar da relevância do setor público no número de instituições e matrículas de educação superior no Brasil, há clara tendência de aumento da participação do mercado privado. De acordo com o MEC e com o Inep, entre 2002 e 2012, houve aumento de $111 \%$ no número de alunos matriculados nas instituições privadas de ensino superior, enquanto, no setor público, houve aumento de $75 \%$. Os dados demonstram que, embora o ensino superior tenha expandido muito nas últimas décadas, este ainda é um promissor espaço para crescimento da educação no país, sobretudo nas regiões Nordeste e Norte. Isso se deve ao fato de referido setor poder se beneficiar das atuais políticas públicas de financiamento, do aumento do número de jovens completando o ensino médio e ainda de um cenário de crescimento econômico, tornando necessária a ampliação da formação de mão-de-obra qualificada, nos próximos anos.

De tal maneira, a complexidade das organizações educacionais suscita questionamentos referentes à área de gestão, o que, certamente, inclui a busca de soluções alternativas para que essas organizações procurem se adequar a um mercado em constante mutação. Finger (1997) afirma que, como a universidade serve a clientes com diferentes necessidades, possui uma tecnologia problemática, rotineira, holística e pouco clara. Assim, e se muitas vezes as universidades não sabem o que fazem, também não sabem como fazer. Os dois centros do poder que existem nas universidades, o acadêmico e o burocrático, consistem, 
respectivamente, no conhecimento exercido pelos especialistas e no eletivo às leis, aos regulamentos e às normas relativas ao ensino e à gerência econômica a cargo dos administradores, que devem levar em consideração a gestão das IES enfatizando suas forças, não deixando de lado a sua missão aparentemente simples, mas, na realidade, complexa, ao considerar as diversidades de aspirações das partes interessadas nas esferas interna e externa da organização.

As Instituições de Ensino Superior (IES) exercem um indispensável papel na sociedade do conhecimento, pondo em circulação o saber nas diferentes áreas da ciência. Logo, a produção do conhecimento nas IES tem o compromisso de formar profissionais para a sociedade por meio de uma proposta acadêmica voltada para o conhecimento que busca o aprendizado contínuo. De acordo com Trigueiro (1968), o MEC é favorável ao crescimento das IES particulares para atender a demanda excedente, privada do ensino público. Entretanto, para isto acontecer, essas IES precisam manter firme o discurso pela qualidade como forma de ter suas ações aprovadas pelos órgãos reguladores, formados principalmente por pessoas pertencentes ao sistema público de educação superior. Na prática, de maneira geral, o que se tem, por um lado, é a fiscalização e as exigências do MEC; e, por outro lado, a criação de novas IES públicas, o que tem sufocado as IES privadas com o acirramento da concorrência e consequente achatamento dos preços. Pode-se assim caracterizar o atual contexto vislumbrado com diferentes políticas e valores vivenciados pelas IES privadas, procurando manter os alunos matriculados, seguindo a tendência da moda e seguindo forte intervenção dos seus proprietários pela tendência de seguir o 'modismo' na definição de seus cursos e currículos.

A Avaliação Institucional deve ser vista como um mecanismo que auxilia no amadurecimento acadêmico. As informações obtidas nesse instrumento devem direcionar ações que objetivem a melhoria contínua da IES - a Avaliação pode ser descrita como um processo contínuo, no qual a IES constrói e produz conhecimento sobre sua própria realidade. Para Dias Sobrinho (2003), as avaliações interna e externa produzem contribuições grandiosas para a gestão institucional: os resultados podem ser discutidos para, então, subsidiar ações de melhoria, de correção e de avanço. Dentro desta perspectiva, define o autor, a avaliação institucional torna-se norteadora para o planejamento estratégico da IES.

Criado pela Lei n. 10.861, de 14 de abril de 2004, o Sistema Nacional de Avaliação da Educação Superior (SINAES) é formado por três componentes principais: a avaliação das instituições, a avaliação dos cursos e a avaliação do desempenho dos estudantes. O SINAES avalia todos os aspectos que giram em torno desses três eixos: o ensino, a pesquisa, a extensão, a responsabilidade social, o desempenho dos alunos, a gestão da instituição, o corpo docente, as instalações e vários outros aspectos. Tal sistema avaliativo, deve-se ressaltar, possui ainda uma série de instrumentos complementares: auto-avaliação, avaliação externa, Exame Nacional de Desempenho dos Estudantes (ENADE), 
Avaliação dos cursos de graduação e instrumentos de informação (censo e cadastro). Os resultados das avaliações possibilitam traçar um panorama da qualidade dos cursos e instituições de educação superior no País. Os processos avaliativos são coordenados e supervisionados pela Comissão Nacional de Avaliação da Educação Superior (CONAES). A operacionalização é de responsabilidade do Instituto Nacional de Estudos e Pesquisas Educacionais Anísio Teixeira (INEP). As informações obtidas com o SINAES são utilizadas pelas IES para orientação da sua eficácia institucional e efetividade acadêmica e social; pelos órgãos governamentais, para orientar políticas públicas; e pelos estudantes, pais de alunos, instituições acadêmicas e público em geral, para orientar suas decisões quanto à realidade dos cursos e das instituições.

O Ministério da Educação tornará público e disponível o resultado da avaliação das instituições de ensino superior e de seus cursos. A divulgação abrange tanto instrumentos de informação como os dados do censo, Conceito Preliminar de Curso (CPC) e Índice Geral de Cursos (IGC) quanto os conceitos das avaliações para os atos de Renovação de Reconhecimento e de Recredenciamento (ciclo trienal do SINAES - com base nos cursos contemplados no ENADE de cada ano). No SINAES, a integração dos instrumentos (auto-avaliação, avaliação externa, avaliação das condições de ensino, ENADE, censo e cadastro) permite a atribuição de conceitos, ordenados numa escala com cinco níveis, a cada uma das dimensões e ao conjunto das dimensões avaliadas. Os resultados da avaliação realizada pelo SINAES subsidiarão os processos de regulação que compreendem os Atos Autorizativos, responsáveis pelo credenciamento da IES, autorização e reconhecimento de cursos; e os Atos Regulatórios, responsáveis pelo recredenciamento da IES e pela renovação de reconhecimento de cursos.

Os resultados considerados insatisfatórios ensejarão a celebração de um protocolo de compromisso firmado entre a IES e o MEC, no qual se estabelecerão encaminhamentos, procedimentos e ações, com indicação de prazos e métodos, a serem adotados pela IES para a superação das dificuldades.

\section{Procedimentos metodológicos}

Esta pesquisa é um estudo descritivo realizado em Instituições de Ensino Superior Privado, classificada, desta forma, como um estudo de múltiplos casos sobre o compartilhamento da informação e do conhecimento. A coleta de dados foi realizada através da utilização das abordagens quantitativa e qualitativa, conjuntamente, o que é denominado de método misto.

A pesquisa de campo para a coleta de dados primários se deu por meio da pesquisa qualitativa através de entrevistas juntos aos coordenadores dos grupos, seguindo um modelo semiestruturado, elaborado para identificar o processo do compartilhamento numa estrutura de grupo de apoio e, após a coleta de dados, a análise se deu 
tendo como parâmetro a técnica de análise de conteúdo. Já a coleta dos dados por meio da pesquisa quantitativa foi realizada através de questionários disponibilizados aos funcionários integrantes dos grupos de apoio das instituições pesquisadas. O questionário seguiu uma estrutura matricial de respostas, utilizando escalas do tipo Likert de cinco pontos.

Quanto à definição dos entrevistados para a aplicação da técnica qualitativa, definiu-se um grupo formado pelos sete gestores de cada Instituição de Ensino Superior Privada que possuem funções de liderança nos processos de implementação e desenvolvimento dos grupos de apoio. Quanto à abordagem quantitativa, o que determinou o tamanho do universo foi a quantidade de colaboradores que participam dos Grupos de Apoio das sete instituições pesquisadas, o que constituiu-se de 49 pessoas durante o período de realização da pesquisa.

As sete instituições de ensino superior definidas para este estudo foram nomeadas da forma abaixo, a fim de resguardá-las:

1 Universidade $A$;

2 Universidade $B$;

3 Centro Universitário C;

4 Centro Universitário D;

5 Faculdade E;

6 Faculdade $F$;

7 Faculdade $\mathrm{G}$.

A definição dessas organizações se deu por atenderem aos seguintes requisitos:

a) possuem um Grupo de Apoio institucionalizado como canal de compartilhamento da informação e conhecimento voltado para os processos de avaliações institucionais;

b) o tempo mínimo de formação destes grupos é de um ano;

c) as instituições possuem um responsável que participou da criação, desenvolvimento e implantação destes grupos.

Para a análise das entrevistas a técnica utilizada foi a e análise das respostas e das categorias produzidas, correlação e agrupamento de informações relevantes e seleção apurada de depoimentos. Para os questionários foi utilizada a análise através do uso de técnicas estatísticas e de programas especializados na realização de cálculos, correlações e análises de regressão. A apresentação e análise dos resultados foi realizada através de tabelas de frequência das respostas obtidas e buscou a conexão entre as respostas dos coordenadores e dos colaboradores dos grupos de apoio. 


\section{Análise dos resultados da pesquisa}

A associação entre os resultados dos dados qualitativos $\mathrm{e}$ quantitativos foi realizada a partir dos dados quantitativos que apresentaram maior e menor avaliação no nível de concordância, apresentando assim um insumo estatisticamente significativo, com o conteúdo associado a estes dados resultantes das entrevistas realizadas na pesquisa qualitativa.

Primeiramente serão apresentadas as questões que tiveram maior nível de concordância.

a) A questão que avaliou se o conhecimento gerado no Grupo de Apoio contribuiu para a melhoria dos processos de avaliações institucionais obteve a maior pontuação entre os respondentes. Todos os Gestores entrevistados afirmaram, de maneira enfática, que as contribuições contribuem para a melhoria dos processos de avaliação das instituições. Para o entrevistado da Faculdade $F$ "as ações e sugestões vindas pelo conhecimento do Grupo permitiram a criação de várias ferramentas de gestão, como relatórios gerenciais e indicadores de performance". Assim, ambos, entrevistados e respondentes, sinalizam que o conhecimento gerado no Grupo de Apoio contribui para a melhoria dos processos de avaliações institucionais, evidenciando desta forma a orientação de Nonaka (1999), para quem o conhecimento é valioso se for aplicável com êxito em atividades criadoras de valor/competências e for utilizável na exploração de oportunidades de negócios.

b) A questão que buscou identificar se o Grupo de Apoio acompanhava de forma contínua e ativa os processos avaliativos da instituição obteve grande nível de concordância entre os participantes. 5 (cinco) dos 7 (sete) entrevistados sinalizaram que seus Grupos acompanham rotineiramente os processos avaliativos de suas instituições. Entretanto, 2 (dois) ressaltaram que é ainda incipiente o acompanhamento de seus Grupos nestes processos. Para o entrevistado do Centro Universitário C "por se tratar de um Grupo relativamente novo, que é visto ainda por alguns setores com desconfiança, todavia acredito que a adesão está dentro do esperado. Com a conquista de bons resultados, não haverá mais hesitação em relação ao processo". A maioria de entrevistados e respondentes acredita que seu Grupo de Apoio acompanha de forma contínua e ativa os processos avaliativos da instituição. Tavares (2011) evidencia que as atividades de um Grupo de Apoio devem ser sistemáticas, acompanhadas e monitoradas de forma a garantir o cumprimento das decisões tomadas no âmbito do grupo. $\mathrm{O}$ autor destaca que práticas bem sucedidas 
de compartilhamento sinalizam para uma institucionalização do processo.

c) A questão que procurava mostrar se o Grupo de Apoio contribuiu para os resultados dos conceitos das avaliações institucionais, avaliações de cursos, ENADE, CPC e IGC apresentou bom nível de concordância. Dois entrevistados disseram ainda não ser possível garantir esta relação. 0 Gestor da Faculdade E descreveu que "por enquanto ainda não havia resultados, pelo pouco tempo que o grupo iniciou suas atividades, mas nas avaliações in loco do INEP o Grupo vinha colaborando". Os demais entrevistados disseram que a contribuição de seus Grupos foi fundamental para os resultados alcançados por suas instituições. O Gestor da Universidade B definiu que "o Grupo atua diretamente para a formação dos conceitos institucionais. Os processos são implementados e acompanhados e junto com outras ações refletem diretamente em especial nas avaliações de cursos, CPC e ENADE". Para Trigueiro (1968), o Ministério da Educação e Cultura (MEC) é favorável ao crescimento das IES particulares para atender a demanda excedente, privada do ensino público. No entanto, para isto acontecer, estas IES precisam manter firme o discurso pela qualidade como forma de ter suas ações aprovadas pelos órgãos reguladores, formados principalmente por pessoas pertencentes ao sistema público de educação superior.

d) A questão que avaliava os principais fatores que prejudicam o processo de compartilhamento no Grupo de Apoio obteve bom nível de concordância entre os respondentes. Para os Gestores e participantes dos Grupos os fatores com maior pontuação foram as diferentes culturas e vocabulários, a diversidade e variedade nas informações, a demora ou falta de um feedback da instituição para os colaboradores e o excesso de trabalho nas atividades de rotina dos membros do Grupo que acabam não tendo a disponibilidade necessária para as atividades e a falta de motivação em compartilhar. O Gestor da Universidade B traduziu que " o maior problema é a resistência de alguns colaboradores na transferência de informações, o repasse de informação de forma incorreta e a alocação de informação num colaborador específico potencializando o efeito negativo no ambiente corporativo". Os fatores diferentes culturas e vocabulários podem ter uma associação direta com o fator diversidade e variedade nas informações, assim como o fator falta de capacidade de absorção pelos participantes pode estar ligado ao apontamento dos entrevistados de que a falta de motivação de alguns colaboradores em compartilhar um conhecimento que é 
deles, muitas vezes, com um enfoque numa vaidade que se desassocia a um comportamento de equipe, é um dos fatores que prejudicam o compartilhamento. Choo (2008) e Davenport (1998) ressaltam que é a cultura que define como o compartilhamento funcionará, ativando posturas e atitudes dos envolvidos por meio da definição de valores, políticas e diretrizes para promover as trocas informacionais no ambiente corporativo. As organizações são formadas por indivíduos que carregam manifestações culturais e que compartilham metas comuns unidas em torno de objetivos, ações e comportamentos; ou seja, representam a própria identidade da organização e produzem a cultura organizacional. O comportamento de certa forma está fundamentado pelo padrão de comportamentos e atitudes que expressam a orientação informacional de uma empresa.

A seguir são apresentadas as questões que tiveram menor nível de concordância:

a) A questão que avaliou se havia interação entre o Grupo de Apoio e os demais canais e sistemas de informações da instituição apresentou baixo nível de concordância. Todos os entrevistados disseram que há relação entre o que é compartilhado entre o Grupo e demais canais da instituição. 0 entrevistado da Faculdade $G$ disse que " o conhecimento do Grupo é disseminado pela instituição, entretanto isso ainda é uma etapa com falhas pois há muitos problemas de comunicação interna". Segundo os entrevistados, a integração do compartilhamento precisa melhorar, visto que a instituição depende do esforço em conjunto de todos os seus colaboradores. Os apontamentos de Davenport (1999) sinalizam que, sempre que os mecanismos disponíveis forem primitivos, em relação à necessidade de informação, será também o sistema como um todo. Quanto maior a eficiência dos canais, maior a utilização deles como instrumento de compartilhamento.

b) A questão cujo objetivo era avaliar se o Grupo de Apoio permitiu que fossem criadas e desenvolvidas competências necessárias para os processos de avaliações institucionais também obteve baixo nível de concordância. A maioria dos Gestores entrevistados discorda da afirmativa, apresentando inclusive quais seriam as competências a serem desenvolvidas, como raciocínio lógico, relacionamento Interpessoal, trabalho em equipe, flexibilidade e negociação e conhecimento da legislação do MEC que orienta os processos avaliativos. Na visão do entrevistado do Centro Universitário D "o mais importante é que o colaborador tem hoje a 
preocupação com o todo e não somente com um único processo, muitas vezes aquele de seu setor de origem". Para McGee e Prusak (1994), a informação é a força motriz na criação de riquezas e prosperidade na economia do conhecimento. Assim, as organizações precisam saber gerir e criar novos conhecimentos para sua competitividade no mercado atual, uma vez que, ao dominarem este processo, terão significativa vantagem sobre as demais.

\section{Considerações finais}

O objetivo geral da presente discussão foi analisar as práticas de compartilhamento da informação e do conhecimento em estruturas de Grupos de Apoio de Instituições de Ensino Superior Privadas em seus processos de avaliações institucionais de forma a perceber a existência de um comportamento preponderante. A pesquisa foi um estudo descritivo realizado em Instituições de Ensino Superior Privado. Foi utilizada uma metodologia mista, com abordagem qualitativa, por meio de entrevistas semiestruturadas realizadas com os gestores e/ou responsáveis de 7 (sete) Grupos de Apoios das instituições selecionadas; e uma abordagem quantitativa, a partir de 44 (quarenta e quatro) questionários estruturados em escalas do tipo Likert de cinco pontos aplicados nos participantes destes grupos. Os resultados apontaram que, de fato, o Ministério da Educação e Cultura (MEC) é favorável ao crescimento das IES particulares para atender a demanda excedente privada do ensino público. A grande questão aqui colocada é que as instituições precisam manter firme o discurso pela qualidade como forma de ter suas ações aprovadas pelos órgãos reguladores, formados principalmente por pessoas pertencentes ao sistema público de educação superior. Em contrapartida, ficou claro também que a busca da qualidade neste segmento está atrelada à conquista e à manutenção de indicadores positivos, conquistados a partir dos conceitos satisfatórios das avaliações institucionais coordenadas pelo INEP/MEC. Em relação as práticas de compartilhamento dos Grupos de Apoio que apontassem para a existência comportamento preponderante, cumpre ressaltar que não foi possível identificar modelo ou fórmula que possa ser padrão em todas as instituições. Ainda assim foi possível apresentar alguns destaques, apresentados a seguir, que, ao serem comparadas nas abordagens qualitativas e quantitativas, geraram insumos relevantes:

a)ainda que não tenha havido consenso sobre a avaliação de que os participantes do Grupo acabam tendo suas competências desenvolvidas, é entendimento de que, ao fazer parte de um grupo em que a dinâmica dos processos é colaborativa e compartilhada, as pessoas acabam criando uma condição para absorverem mais conhecimento e melhorarem seu desempenho. 
b)é clara a evidência de que ao participar do grupo o aprendizado não fica somente no âmbito dele, uma vez que, ao se transformarem em conhecimento, um conjunto de ações e procedimentos acaba sendo compartilhado, levando de fato à institucionalização dos processos.

c)os grupos de apoio formalizam o conhecimento por meio de procedimentos que variam de acordo com a instituição. De modo geral, são utilizados recursos como manuais colaborativos, instruções, regulamentos, descritivo de normas e resoluções, cartilhas com diretrizes, atas de reuniões, relatórios, formulários e informativos.

d)é consenso que o conhecimento gerado no Grupo de Apoio contribui para a melhoria dos processos de avaliações institucionais. É necessário destacar que a elevada competição presente no ambiente das Instituições de Ensino Superior Privadas as tem levado a buscar variadas alternativas no sentido da elevação de sua produtividade e qualidade de suas operações. Quando um grupo sinaliza que tem contribuído para a melhoria dos processos, isto significa que há identificação de que o benefício do conhecimento proporciona vantagem sustentável, gerando retornos crescentes e continuados.

e)a maioria dos grupos de apoio não possui um alinhamento com os demais canais e sistemas de informações das instituições. Esta falta de integração compromete o compartilhamento e o aprendizado coletivo na instituição, uma vez que, quando não é adequadamente realizado, prejudica a melhoria da qualidade dos produtos e a qualidade dos serviços por ela prestados.

f)os fatores que comprometem o compartilhamento do conhecimento no grupo de apoio são a diversidade e a variedade nas informações; a demora ou a falta de retorno de respostas por parte da instituição para os participantes do grupo; excesso de trabalho nas atividades de rotina dos membros do Grupo, que acabam não tendo a disponibilidade necessária para as atividades de seu Grupo; e a falta de motivação de alguns integrantes em compartilhar um conhecimento que é deles.

g)os Grupos de Apoio implementam procedimentos específicos para subsidiar os processos avaliativos de suas instituições. Em alguns casos, estes procedimentos acabam saindo dos limites do grupo, e são criadas estruturas próprias para subsidiar os processos, como departamentos e/ou setores que geram indicadores e beneficiam toda a instituição com informações de maneira integrada e consolidada. 
h)os grupos de Apoio acompanham de forma sistemática e dinâmica os processos avaliativos das instituições, buscando desta forma o cumprimento das decisões tomadas no âmbito do grupo. As avaliações institucionais fazem parte do fluxo de rotinas das instituições e geram informações para o SINAES. Estas informações acabam direcionando ações que objetivem a melhoria contínua das instituições. Ou seja, as avaliações podem ser descritas como um processo contínuo, no qual uma instituição constrói e produz conhecimento sobre sua própria realidade.

i)é relevante a contribuição dos Grupos de Apoio nos resultados dos conceitos das avaliações de suas instituições. Os grupos atuam diretamente na formação dos conceitos institucionais, refletindo em especial nas avaliações de cursos, CPC e ENADE, fator indispensável para que as instituições tenham suas ações aprovadas pelos órgãos reguladores. Há evidências de que o grupo de apoio contribui para resultados satisfatórios dos conceitos oriundos das avaliações institucionais. Cientes desta contribuição, as instituições inclusive criam, implementam e controlam processos que permitem aos participantes do grupo, utilizando como principal recurso a informação e o conhecimento, terem uma significativa vantagem competitiva na tomada de decisões.

Por fim, cabe ressaltar que este estudo se constitui apenas como uma contribuição para a temática de compartilhamento da informação e do conhecimento. Dada a importância do tema, considera-se que há muito ainda que percorrer no campo da pesquisa nesta área, que se apresenta como um campo fértil de trabalho para outros pesquisadores.

\section{Referências}

ADLER, P. S.; HECKSCHER, C. Towards collaborative community. In: ADLER, P. S., HECKSCHER, C. The firm as a collaborative community: reconstructing trust in the knowledge economy. Oxford, England: Oxford University Press, 2006. p. 11-105.

BRASIL. Ministério da Educação. Lei 10.861, de 14 de abril de 2004. Institui o Sistema Nacional de Avaliação da Educação Superior - SINAES e dá outras providências. Diário Oficial da União, Brasília, 2014. Disponível em: <http://www.planalto.gov.br/ccivil_03/_ato20042006/2004/lei/l10.861.htm>. Acesso em: 12 out. 2014.

CARVALHO, A. M. A. Conformação de um regime de informação: a experiência do Arranjo Produtivo Local de Eletrônica de Santa Rita do Sapucaí - Minas Gerais. 2009. Tese (Doutorado em Ciência da Informação) - Escola da Ciência da Informação, Universidade Federal de Minas Gerais, Belo Horizonte, 2009. 
CHOO, C. W. A organização do conhecimento: como as organizações usam a informação para criar significado, construir conhecimento e tomar decisões. 3. ed. São Paulo: Senac, 2003.

DAVENPORT, T. H.; PRUZAK, L. Conhecimento empresarial: como as organizações gerenciam seu capital intelectual. 3. ed. Rio de Janeiro: Campus, 1998.

DIAS SOBRINHO, J. Avaliação da educação superior, regulação e emancipação. In: DIAS SOBRINHO, J.; RISTOFF, D. (Org.). Avaliação e compromisso público. Florianópolis: Insular, 2003. p. 96-112.

DRUCKER, P. F. Sociedade pós-capitalista. São Paulo: Pioneira, 1993.

FINGER, A. P. Gestão de universidades: novas abordagens. Brasilia: Champagnat, 2007.

FLEURY, O. M. M. J. Gestão estratégica do conhecimento: integrando aprendizagem, conhecimento e competências. São Paulo: Atlas, 2001.

FRANCIS, D.; YOUNG, D. Improving work groups: a practical manual for team building. San Diego, California: Pfeiffer e Company, 1992.

INSTITUTO NACIONAL DE ESTUDOS E PESQUISAS EDUCACIONAIS ANÍSIO TEIXEIRA (INEP). SINAES. Disponível em: <http://portal.inep.gov.br/superior-sinaes>. Acesso em: 15 jan. 2016.

LEEHESVIRTA, T. Learning processes in a work organization: from individual to collective and/orvice versa? Journal of Workplace Learning, v. 16p. 92-100, 2004.

McGEE, J. V.; PRUSAK, L. Gerenciamento estratégico da informação. 2. ed. Rio de Janeiro: Campus, 1994.

NISEBAUM, H. Perspectivas em ciências da informação. Belo Horizonte: UFMG, 2002.

NONAKA, I.; TAKEUCHI, H. Criação do conhecimento na empresa. Rio de Janeiro: Campus, 1997.

NONAKA, I. A Dynamic theory of organizational knowledge creation. Organization Science, Linthicum, v. 5, n. 1, p. 14-37, 1999.

NONAKA, I. The Knowledge-creating company. Harvard Business Review, New York, v. 69, n. 6, p. 96-104, Nov./Dec. 2001.

STEWART, T. Capital intelectual: a nova vantagem competitiva das empresas. Rio de Janeiro: Campus, 1998.

TAVARES, M. C. Gestão estratégica. 3. ed. São Paulo: Atlas, 2011.

TRIGUEIRO MENDES, D. Expansão do ensino superior no Brasil. Documenta, n. 91, p. 26-70, set. 1968.

WENGER, E. C.; SNYDER, W.M. Comunidades de prática: a fronteira organizacional. In: HARVARD BUSINESS REVIEW (Org.). Aprendizagem organizacional. Rio de Janeiro: Campus, 2001. 